\title{
Safety and Dose Study of Targeted Lung Denervation in Moderate/Severe COPD Patients
}

\author{
Arschang Valipour $^{\mathrm{a}}$ Pallav L. Shah ${ }^{\mathrm{b}}$ Christophe Pison $^{\mathrm{c}}$ Vincent Ninane $^{\mathrm{d}}$ \\ Wim Janssens ${ }^{\mathrm{e}}$ Thierry Perez $^{f}$ Romain Kessler $^{\mathrm{g}}$ Gaetan Deslee $^{\mathrm{h}}$ \\ Justin Garner ${ }^{b}$ Christine Abele ${ }^{a}$ Jorine E. Hartman ${ }^{i}$ Dirk- \\ Jan Slebos ${ }^{i}$ On behalf of the AIRFLOW-1 Study Group
}

\begin{abstract}
a Department of Respiratory and Critical Care Medicine, Ludwig-Boltzmann-Institute for COPD and Respiratory Epidemiology, Otto-Wagner-Spital, Vienna, Austria; ${ }^{\mathrm{b}}$ Royal Brompton and Harefield NHS Trust, Chelsea and Westminster Hospital, and Imperial College, London, UK; ' CService Hospitalier Universitaire Pneumologie Physiologie, Centre Hospitalier Universitaire Grenoble Alpes, InsermU1055, Université Grenoble Alpes, Grenoble, France; ${ }^{d} \mathrm{CHU}$ Saint-Pierre, Université libre de Bruxelles, Bruxelles, Belgium; e Department of Respiratory Diseases, KU Leuven, University Hospitals Leuven, Leuven, Belgium; ${ }^{f} \mathrm{CHU}$ Lille, Center for Infection and Immunity of Lille, INSERM U1019, CNRS UMR 8204 Univ Lille Nord de France, Lille, France; ${ }^{9}$ Service de Pneumologie, Nouvel Hôpital Civil, Université de Strasbourg, Strasbourg, France; ${ }^{\text {h } C H U ~ d e ~ R e i m s, ~ H o ̂ p i t a l ~ M a i s o n ~ B l a n c h e, ~ I N S E R M ~ U M R S ~ 1250, ~ S e r v i c e ~ d e ~ P n e u m o l o g i e, ~}$ Reims, France; 'Department of Pulmonary Diseases, University of Groningen, University Medical Center Groningen, Groningen, The Netherlands
\end{abstract}

\section{Keywords}

Bronchoscopy · Radiofrequency ablation .

Parasympathectomy · Lung disease obstructive ·

Acetylcholine

\begin{abstract}
Rationale: Targeted lung denervation (TLD) is a novel bronchoscopic treatment for the disruption of parasympathetic innervation of the lungs. Objectives: To assess safety, feasibility, and dosing of TLD in patients with moderate to severe COPD using a novel device design. Methods: Thirty patients with COPD (forced expiratory volume in $1 \mathrm{~s} 30-60 \%)$ were 1:1 randomized in a double-blinded fashion to receive TLD with either 29 or 32 W. Primary endpoint was the rate of TLDassociated adverse airway effects that required treatment through 3 months. Assessments of lung function, quality of life, dyspnea, and exercise capacity were performed at baseline and 1-year follow-up. An additional 16 patients were en-
\end{abstract}

rolled in an open-label confirmation phase study to confirm safety improvements after procedural enhancements following gastrointestinal adverse events during the randomized part of the trial. Results: Procedural success, defined as device success without an in-hospital serious adverse event, was $96.7 \%$ (29/30). The rate of TLD-associated adverse airway effects requiring intervention was $3 / 15$ in the $32 \mathrm{~W}$ versus $1 / 15$ in the $29 \mathrm{~W}$ group, $p=0.6$. Five patients early in the randomized phase experienced serious gastric events. The study was stopped and procedural changes made that reduced both gastrointestinal and airway events in the subsequent phase of the randomized trial and follow-up confirmation study. Improvements in lung function and quality of life were observed compared to baseline values for both doses but were not statistically different. Conclusions: The results demonstrate acceptable safety and feasibility of TLD in patients with COPD, with improvements in adverse event rates after procedural enhancements.

(C) 2019 The Author(s)

Published by S. Karger AG, Basel

\begin{tabular}{ll}
\hline KARGER & $\begin{array}{l}\text { ( } 2019 \text { The Author(s) } \\
\text { Published by S. Karger AG, Basel }\end{array}$ \\
E-Mail karger@karger.com & $\begin{array}{l}\text { This article is licensed under the Creative Commons Attribution- } \\
\text { NonCommercial-NoDerivatives 4.0 International License (CC BY- } \\
\text { NC-ND) (http://www.karger.com/Services/OpenAccessLicense). } \\
\text { Usage and distribution for commercial purposes as well as any dis- } \\
\text { tribution of modified material requires written permission. }\end{array}$
\end{tabular}

Dirk-Jan Slebos, MD, $\mathrm{PhD}$

Department of Pulmonary Diseases

University Medical Center Groningen, University of Groningen

NL-9700 RB Groningen (The Netherlands)

E-Mail d.j.slebos@int.umcg.nl 


\section{Introduction}

Acetylcholine released from parasympathetic nerves in the lung is a key mediator of pathology in obstructive airways diseases through its induction of smooth muscle contraction, facilitation of reflex bronchoconstriction, incitement of mucus overproduction, and contribution to overall airway inflammation [1-4]. Changes in autonomic activity and efferent parasympathetic overactivity have been identified as a source of dysfunction in obstructive airways disease [5-10].

Pharmacologic disruption of parasympathetic lung innervation by inhaled anticholinergic therapies is the mainstay of chronic obstructive pulmonary disease (COPD) treatment. Permanent disruption or attenuation of parasympathetic nerves in patients with lung disease has the potential to provide long-lasting anticholinergic effects and consistent relief of obstructive lung disease symptoms/exacerbations. Targeted lung denervation (TLD) is a novel bronchoscopic therapy designed to attenuate the parasympathetic pulmonary branches of the vagus nerve that run along the outside of the mainstem bronchi, thereby disrupting the innervation to the entire lung. Early feasibility studies demonstrated that TLD could be performed safely providing a clinical benefit for COPD patients [11-13].

Major enhancements were made to the TLD system and device (online suppl. Fig. S1; for all online suppl. material, see www.karger.com/doi/10.1159/000500463) after the initial feasibility studies $[11,13]$. These changes include compatibility of the catheter with flexible bronchoscopy and a larger electrode to decrease procedure time. The AIRFLOW-1 trial is the first study to evaluate the safety of this second-generation version of the device for safety, treatment dose, and device/procedure performance.

\section{Methods}

\section{Study Design}

The AIRFLOW-1 study was initiated to assess airway safety and to evaluate TLD energy dose by randomizing between 2 selected doses ( 29 vs. $32 \mathrm{~W}$ ). Thirty subjects were randomized 1:1, in a double-blind, multi-center study conducted at 10 Western European sites between August 4, 2014, and July 16, 2015. Major entry criteria included COPD defined as the ratio of post-bronchodilator forced expiratory volume in $1 \mathrm{~s}\left(\mathrm{FEV}_{1}\right)$ to forced vital capacity (FVC) of $\leq 0.70$ and post-bronchodilator $\mathrm{FEV}_{1}$ of $30-60 \%$ of predicted normal values, age $\geq 40$ and $\leq 75$ years, persistent symptoms indicated by either Modified Medical Research Council (mMRC) grade $\geq 2$ and/or COPD assessment test (CAT) score $\geq 10$, and re- versibility to anticholinergic medications as demonstrated by a positive relative change in $\mathrm{FEV}_{1}$ and/or FVC of $>12 \%$ and $>200 \mathrm{~mL}$ following inhalation of $80 \mu \mathrm{g}$ ipratropium bromide. A complete listing of all study inclusion and exclusion criteria can be found in online supplement Table S1.

\section{Procedures}

Following informed consent and screening, subjects had baseline testing after a washout period from their inhaled bronchodilators consisting of $\geq 7$ days for long-acting muscarinic antagonists, $72 \mathrm{~h}$ for ultra-long-acting beta agonist, $24 \mathrm{~h}$ for long-acting beta agonist, and $12 \mathrm{~h}$ for short-acting beta agonist. Current American Thoracic Society (ATS)/European Respiratory Society (ERS) guidelines were followed for pulmonary function testing [14]. The St. George's Respiratory Questionnaire (SGRQ-C) [15], the CAT [16], and the EuroQol five-dimension five-level scale utility index and visual analogue scale [17] were used to assess quality of life and health status. Baseline and Transition Dyspnea Index and mMRC Scale [18] were used to assess dyspnea. Cycle ergometry training was implemented during washout using ATS/ACCP guidelines [19] to first establish a baseline maximum work rate $\left(\mathrm{W}_{\max }\right)$ off drugs and subsequently as an endurance test conducted at a constant work rate of $75 \%$ of the $\mathrm{W}_{\max }$ [20]. Baseline chest CT-scans were obtained and analyzed by an independent core lab (VIDA Diagnostics, Coralville, IA, USA) to assess bronchial anatomy and the level of emphysema (using automated emphysema quantification at a threshold of $-950 \mathrm{HU})$, to rule out other pulmonary abnormalities.

Follow-up bronchoscopy was performed on all patients at 3 months to evaluate airway wall effects. At 12 months, all baseline testing was repeated in all available patients for comparison to pretreatment baselines under the same conditions after bronchodilator washout. Safety events were monitored continuously during the follow-up period.

\section{Randomization and TLD Treatment}

All patients underwent TLD to both lungs in a single procedure under general anesthesia. The choice of airway access (rigid bronchoscopy, endotracheal tube, laryngeal mask) and mode of ventilation was left at the discretion of the operator.

Chest CT-scans obtained at baseline and bronchoscopic inspection at the time of the procedure were used to assess airway compatibility with the dual cooled radiofrequency (RF) catheter prior to randomization. After confirmation of airway compatibility, randomization was performed using tamper-resistant sealed envelopes that contained letter codes that were entered into the console to deliver the appropriate RF power level for treatment. This allowed for a triple-blind study design to be conducted with the treating physician, subject, and follow-up physician all unaware of the exact RF energy level provided. After randomization, the treatment catheter was advanced through the bronchoscope, and circumferential treatment was achieved by activating the electrode in up to 4 positions per bronchi (online suppl. Fig. S1). Bronchoscopic and fluoroscopic visualization was used to guide electrode placement before and during energy delivery. All patients were prescribed $25-30 \mathrm{mg}$ prednisone and $500 \mathrm{mg}$ of azithromycin daily for 1 day before and 2 days after the procedure. All subjects remained on standard dosing of tiotropium bromide for a minimum of 90 days. No additional post procedure medication was required. Investigators could treat respiratory symptoms per stan- 
dard of care and published guidelines. Time to discharge was left to institutional practice.

\section{Open-Label Confirmation Study Following Procedural}

Enhancements

After treatment of the first 13 subjects in the randomized dose evaluation phase, reports of gastric adverse events led to a suspension of treatments and a detailed investigation of all pertinent events, procedure videos, fluoroscopic images, and records from the TLD system. The investigation suggested that these events were related to inadvertent injury to esophageal branches of the vagus nerve during treatment. Following approval by the independent data monitoring committee and protocol steering committee, protocol, procedural, and training enhancements were implemented to ensure optimal placement, visualization, and confirmation of the electrode position relative to the esophagus prior to activation to mitigate against further gastric events. The new procedure version included fluoroscopic visualization and active measurement of the distance between the electrode and the outer wall of the esophagus, by use of a commercially available esophageal balloon (CRE ${ }^{\mathrm{TM}}$, Boston Scientific or Hercules ${ }^{\circledR}$ 3, Cook Medical) filled to low pressure with a contrast agent and saline, to assist in avoiding the thermally sensitive vagus nerve (online suppl. Table S2). To further mitigate gastrointestinal side effects, low power (26 $\mathrm{W})$ was used for treatment positions close to the main carina. The treatment algorithm used per protocol is provided in online suppl. Table S2.

After appropriate protocol amendment and ethics approvals, 17 patients continued enrollment in the randomization dose study and 16 additional patients were enrolled and treated in an openlabel confirmation study between November 2, 2015, and June 14, 2016 (after the dosing phase was completed) to confirm the impact of protocol, procedural, and training enhancements on gastric safety. Patient inclusion and exclusion criteria as well as baseline and follow-up testing were identical to the randomized dose evaluation phase with the additional exclusion of patients with a history of prior abdominal surgical procedures, a baseline gastroparesis cardinal symptom index score $\geq 18$, as part of the patient assessment of gastrointestinal disorders symptom severity index [21] prior to treatment, or recent ( $<3$ months ago) narcotic use.

\section{Study Endpoints}

The primary safety endpoint for the randomized dose evaluation phase was the rate of TLD-associated adverse airway effects that required a therapeutic intervention (defined as the administration of antibiotics, conduction of another diagnostic test to assess the treatment area, or an endoscopic procedure or surgery to treat findings) through 3 months posttreatment.

Secondary endpoints included procedural success (defined as the ability to insert and place the catheter to its intended locations and intact removal without the report of an in-hospital serious adverse event [SAE]), overall adverse events, and change from baseline to 1-year for pulmonary function tests, health-related quality of life, dyspnea, and exercise capacity assessments. At the 1-year follow-up visit, patients were tested following a washout period identical to baseline testing. The primary safety endpoint for the open-label confirmation phase was the rate and frequency of adverse events through 1-month posttreatment compared to the randomized dose evaluation phase. Secondary endpoints were identical to the randomized dose evaluation phase.

\section{Statistical Methods}

As no primary statistical hypothesis was proposed, the study sample size was not based on formal statistical power calculations. The sample size of 30 (15 subjects per dose) in the randomized dosing group would not allow for the detection of differences between groups in pulmonary function testing. A sample size of 15 in the open-label confirmation study was selected to appropriately compare rates and frequency of adverse events to the optimal dose group selected from the randomized dosing phase. All $p$ values were presented for informational purposes only. According to the prespecified analysis plan, continuous data were summarized using means and SD. Categorical data were tabulated, with counts and percentages. All monitored and available data were summarized, with no imputation for missing data. The final analyses were conducted using SAS version 9.3 (SAS Institute Inc., Cary, NC, USA) by an independent statistical group (NAMSA, Minneapolis, MN, USA).

\section{Safety Monitoring}

Each patient signed a written consent form. Study approval was obtained by local Ethics Committees and in accordance with the Declaration of Helsinki (1996), Good Clinical Practice guidelines, and any local requirements. A protocol steering committee and an independent data monitoring committee oversaw protocol management and overall safety for the study. An independent clinical events committee adjudicated all reported SAEs and any non-serious event deemed relevant by the study safety officer, using original and monitored source documentation from the site.

This trial is registered with ClinicalTrials.gov, number NCT02058459.

\section{Results}

\section{Randomized, Dose Evaluation Study}

Patients and Procedure

Baseline characteristics are shown in Table 1. Patients included had evidence of moderate-severe airflow obstruction, and other characteristics were well balanced between the $29 \mathrm{~W}(n=15)$ and $32 \mathrm{~W}(n=15)$ treatment groups.

Procedural details are shown in Table 1. Acute procedure success was $96.7 \%$ (29/30) with 1 report of aphonia following TLD due to the introduction of a rigid bronchoscope, which did not require hospitalization but required speech therapy and a 1-day lipofilling of the vocal cord for treatment. The patient had a normal vocal cord exam at 6-month follow-up. In total, 90\% (27/30) of patients were discharged within $24 \mathrm{~h}$ after the procedure. One-year follow-up data were available for $80 \%$ (24/30) of the patients (Fig. 1).

\section{Safety Outcomes}

Immediate post procedure airway inspection was performed in all patients, and typical findings consisted of 
Table 1. Patient baseline characteristics and procedure characteristics

\begin{tabular}{|c|c|c|c|}
\hline & \multicolumn{2}{|l|}{ Dosing group } & \multirow{2}{*}{$\frac{\text { Confirmation group }}{32 \mathrm{~W}(n=16)}$} \\
\hline & $29 \mathrm{~W}$ group $(n=15)$ & $32 \mathrm{~W}$ group $(n=15)$ & \\
\hline Age, years & $61(8)$ & $64(6)$ & $63(6)$ \\
\hline Male, $n(\%)$ & $9(60)$ & $4(27)$ & $6(38)$ \\
\hline Ethnic origin, white, $n(\%)$ & $14(93)$ & $15(100)$ & $16(100)$ \\
\hline Smoking pack-years & $43(23)$ & $47(28)$ & $41(11)$ \\
\hline $\mathrm{BMI}$ & $25(3)$ & $25(3)$ & $26(3)$ \\
\hline $\mathrm{FEV}_{1}$ post bronchodilator, $\mathrm{L}$ & $1.11(0.3)$ & $1.09(0.2)$ & $0.97(0.2)$ \\
\hline $\mathrm{FEV}_{1} / \mathrm{FVC}$ post bronchodilator, $\mathrm{L}$ & $35(9)$ & $37(8)$ & $33(5)$ \\
\hline Reversibility peak change in $\mathrm{FEV}_{1}, \%$ & $19(7)$ & $20(10)$ & $22(11)$ \\
\hline $\mathrm{FEV}_{1}$ at washout, $\mathrm{L}$ & $0.88(0.3)$ & $0.86(0.2)$ & $0.81(0.2)$ \\
\hline $\mathrm{FEV}_{1}$ at washout, $\%$ & $31(5)$ & $36(10)$ & $32(6)$ \\
\hline FVC at washout, L & $2.73(0.8)$ & $2.52(0.5)$ & $2.62(0.7)$ \\
\hline FVC at washout, $\%$ & $77(12)$ & $84(11)$ & $85(17)$ \\
\hline Cycle endurance, $\min$ & $7.01(4)$ & $9.42(9)$ & $8.55(9)$ \\
\hline Emphysema, \%* & 31 & 27 & 32 \\
\hline \multicolumn{4}{|l|}{ Airway access, $n(\%)$} \\
\hline Endotracheal tube & $11(73)$ & $9(60)$ & $12(75)$ \\
\hline Rigid bronchoscope & $4(26)$ & $6(40)$ & $3(19)$ \\
\hline Laryngeal mask & $0(0)$ & $0(0)$ & $1(6)$ \\
\hline \multicolumn{4}{|l|}{ Left lung treatment, $n(\%)$} \\
\hline$\geq 4$ activations & $14(93)$ & $15(100)$ & $15(94)$ \\
\hline$<4$ activations & $1(7)$ & $0(0)$ & $1(6)$ \\
\hline \multicolumn{4}{|l|}{ Right lung treatment, $n(\%)$} \\
\hline$\geq 4$ activations & $13(87)$ & $12(80)$ & $9(56)$ \\
\hline$<4$ activations & $2(13)$ & $3(20)$ & $7(45)$ \\
\hline Average catheters used & $1.3 \pm 0.5$ & $1.5 \pm 1.1$ & $1.44 \pm 0.5$ \\
\hline Total procedure time, min & $72 \pm 22$ & $67 \pm 20$ & $67 \pm 14$ \\
\hline Total fluoroscopy time, $\min$ & $5.0 \pm 3.5$ & $3.9 \pm 4.0$ & $4.4 \pm 1.5$ \\
\hline Discharge within $24 \mathrm{~h}, n(\%)$ & $14(93)$ & $13(87)$ & $15(94)$ \\
\hline $\begin{array}{l}\text { Data are mean (SD) unless stated } \\
* \text { Core lab measurements using }-9 \\
\text { No statistical difference between } 3 \\
\text { BMI, body mass index; FEV }{ }_{1} \text {, forc }\end{array}$ & $\begin{array}{l}\text { wise. } \\
\text { U (VIDA Diagnosti } \\
29 \mathrm{~W}(p>0.05) \text { for } \\
\text { piratory volute in } 1\end{array}$ & $\begin{array}{l}\text { Coralville, IA, US } \\
\text { iny parameter. } \\
\text { FVC, forced vital ca }\end{array}$ & \\
\hline
\end{tabular}

whitish mucosal blanching at the site of treatment. Follow-up bronchoscopy at 3 months was performed on 14 patients in the $32 \mathrm{~W}$ group and 13 patients in the $29 \mathrm{~W}$ group. Typical findings consisted of normal airway. Figure 2 shows an example of typical early airway findings posttreatment and during 3-month follow-up airway inspection.

Four subjects, 1 in the $29 \mathrm{~W}$ group (6.6\%) and 3 in the $32 \mathrm{~W}$ group (20\%) met the primary safety endpoint. In the $29 \mathrm{~W}$ group, 1 subject was found to have a small $(\sim 1$ $\mathrm{mm}$ ) nodule at a treatment site in the right main stem during the 3-month airway inspection and prompted the physician to repeat bronchoscopy at 6 months at which time the nodule had resolved. In the $32 \mathrm{~W}$ group, 1 patient was found to have a small $(\sim 1 \mathrm{~mm})$ nodule at a treatment site, which resolved by the 6-month follow-up without intervention. A second patient was prophylactically given steroids and antibiotics in response to a larger area of whitish mucosal blanching immediately posttreatment with normal healing observed at the 3-month airway inspection. The third patient developed pneumonia that was poorly responsive to antibiotics, which led to intensive care admission with bronchoscopy and the discovery of a deep ulceration at the medial side of the right main stem bronchus with a mucosal fistula through the thin tissue of the carina and a partial occlusion of the right upper lobe bronchus. Repeat assessments showed progressive local healing with a complete clinical recovery of the patient. 


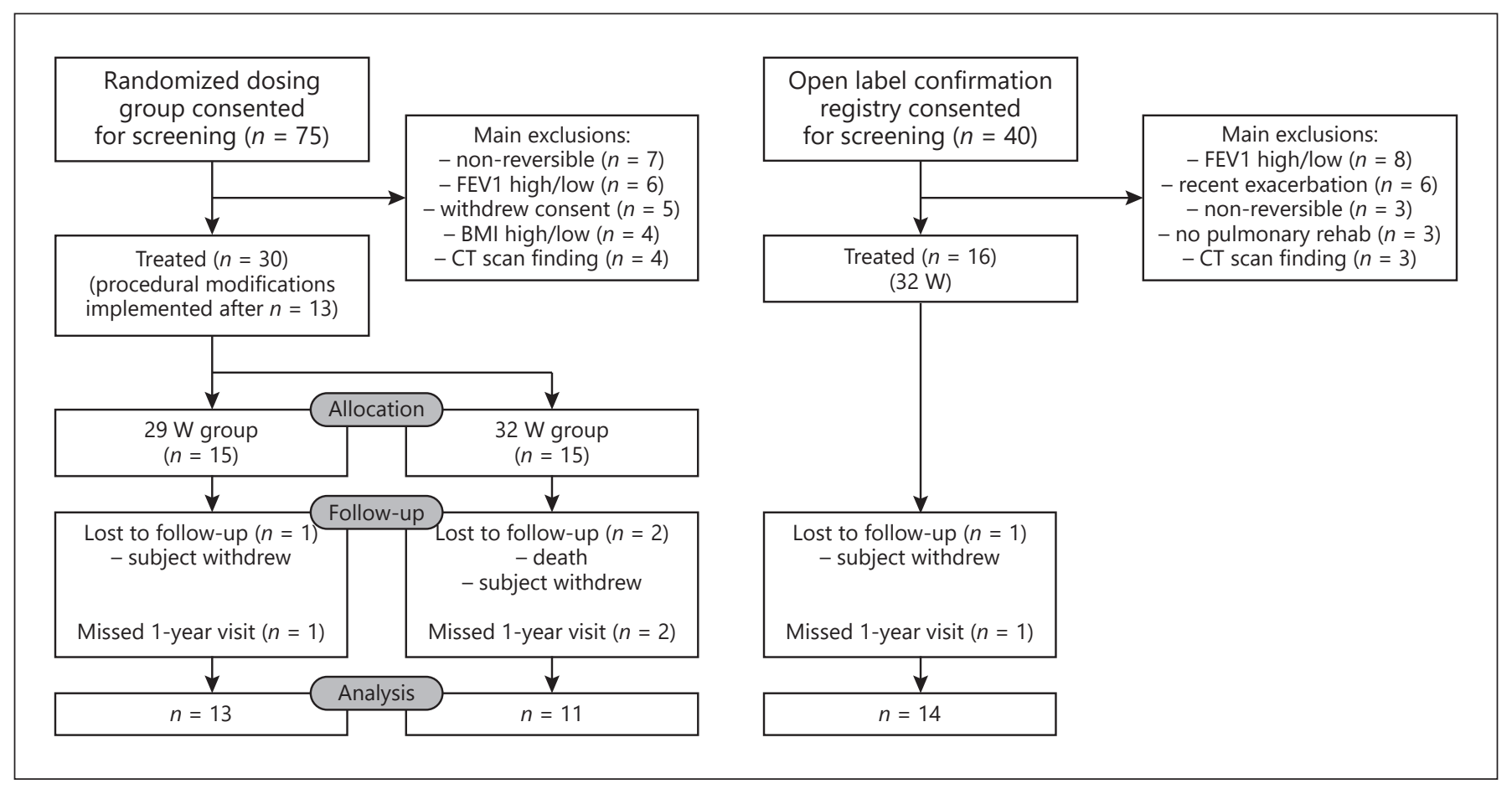

Fig. 1. Study flow charts for randomized dose evaluation and open-label confirmation patients.

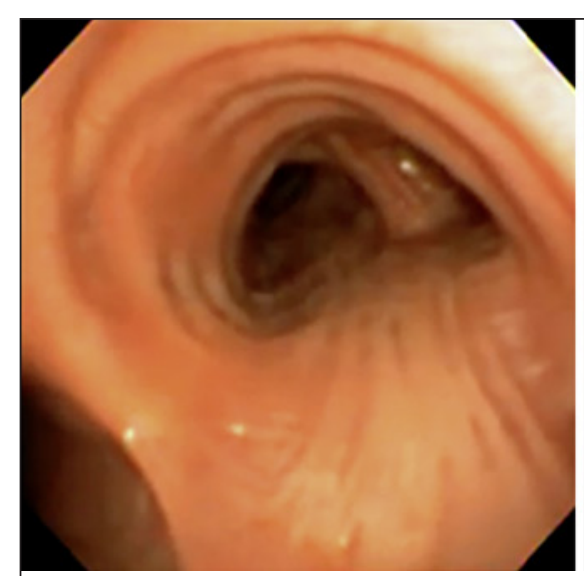

Baseline: right bronchus prior to treatment

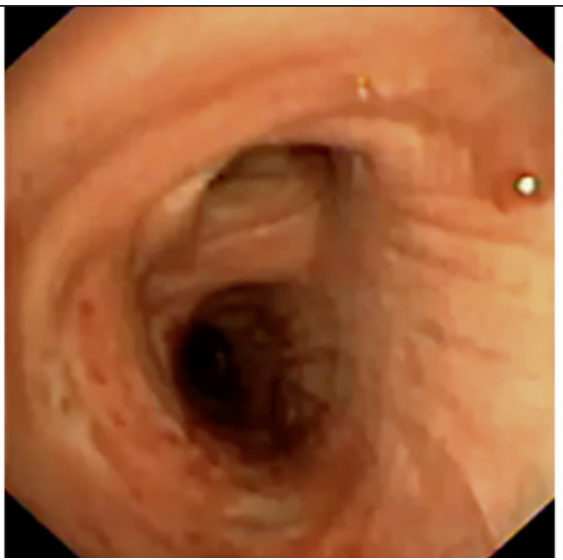

Acute effect after treatment

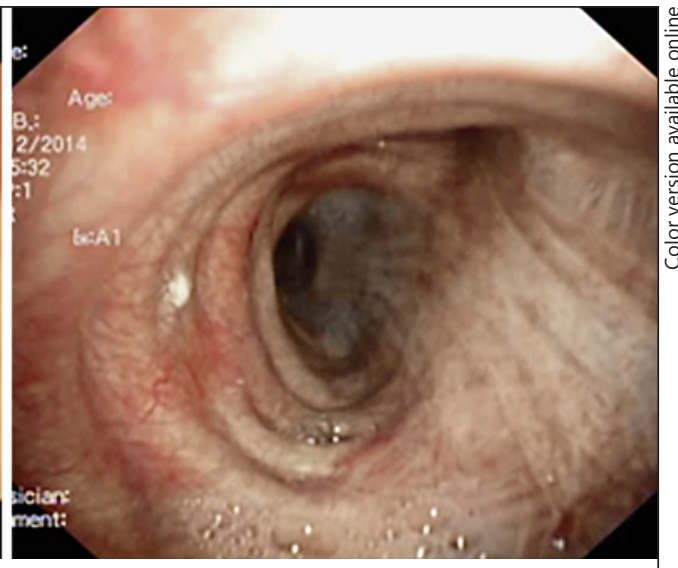

3-month follow-up

Fig. 2. Example of typical airway response to TLD over time. Typical airway findings following the TLD procedure. The 3 images from left to right depict the right main bronchus of a treated patient immediately prior to treatment, the acute effect immediately following treatment, and the effect at 3-month bronchoscopic follow-up.

A complete listing of all SAEs reported out to 1 year is provided in Table 2 . There was 1 death due to aortic dissection and rupture 6 days posttreatment. The patient had a history of dissection and stenting 7 years prior to the current intervention, which was assessed by autopsy to be unrelated to TLD. Another patient experienced a
non-ST-elevation myocardial infarction at 68 days posttreatment that was not related to the procedure. Overall SAE rates were numerically higher in the $29 \mathrm{~W}$ group than in the $32 \mathrm{~W}$ group with impaired gastric emptying in 5 patients ( $16.6 \%$ of treated population) being the most commonly reported. Four of these 5 patients treated un- 
Table 2. Primary endpoint and 12-month SAEs

\begin{tabular}{|c|c|c|c|}
\hline & \multicolumn{2}{|l|}{ Dosing group } & \multirow{2}{*}{$\frac{\text { Confirmation group }}{32 \mathrm{~W}(n=16)}$} \\
\hline & $29 \mathrm{~W}(n=15)$ & $32 \mathrm{~W}(n=15)$ & \\
\hline Primary endpoint ${ }^{\#}$ (\% of patients) & $1(6.6)$ & $3(20)$ & $0(0)$ \\
\hline Total, SAEs (patients) & $16(9)$ & $14(5)$ & $9(5)$ \\
\hline Pulmonary, events (patients) & $5(3)$ & $6(3)$ & $5(4)$ \\
\hline COPD exacerbation & 3 & 3 & 2 \\
\hline Pneumonia & 1 & 1 & 1 \\
\hline Bronchitis & - & - & 1 \\
\hline Cough & - & - & 1 \\
\hline Aphonia & 1 & - & - \\
\hline Bronchial fistula & - & 1 & - \\
\hline Non-small-cell lung cancer & - & 1 & - \\
\hline Gastrointestinal, events (patients) & $7(6)$ & $4(3)$ & $0(0)$ \\
\hline Impaired gastric emptying & 3 & 2 & - \\
\hline Epigastric discomfort & - & 1 & - \\
\hline Nausea & 1 & - & - \\
\hline Duodenal ulcer hemorrhage & 1 & - & - \\
\hline Cholecystitis acute & - & 1 & - \\
\hline Colitis & 1 & - & - \\
\hline Diverticulitis & 1 & - & - \\
\hline Cardiac, events (patients) & $0(0)$ & $2(2)$ & $0(0)$ \\
\hline Aortic dissection, death & - & 1 & - \\
\hline Acute myocardial infarction & - & 1 & - \\
\hline Other, events (patients)* & $4(3)$ & $2(2)$ & $3(2)$ \\
\hline
\end{tabular}

\footnotetext{
\# Percentage of patients with bronchoscopic airway effects that required a therapeutic intervention through 3-month posttreatment.

* Other events included: 29 W Dosing Group: urine retention, iron deficiency anemia, depression, and bursitis. $32 \mathrm{~W}$ Dosing: non-cardiac chest pain, arthritis; $32 \mathrm{~W}$ Confirmation Group: non-cardiac chest pain, tendonitis, and hypoglycemia.

SAE, serious adverse event.
}

der the original procedure design continued to experience symptoms of impaired gastric emptying 1-year post procedure. Of these 4 patients, 3 experienced amelioration of symptoms with treatment before their 1-year follow-up and complete resolution of impaired gastric emptying during follow-up beyond 1 year. A reduction in both occurrence and severity of gastric events was noted in the remaining subjects treated after procedural enhancements, both in the randomized dose evaluation phase and in the open-label study (Table 1 and online suppl. Table S4). A complete list of all adverse events is displayed in online supplemental Table S3.

\section{Efficacy Outcomes}

At 1 year during the bronchodilator washout study visit, improvements in $\mathrm{FEV}_{1}$ of $94.2 \pm 228 \mathrm{~mL}(p=0.18)$, FVC $212 \pm 497 \mathrm{~mL}(p=0.17)$, SGRQ-C $-7.5 \pm 10.3(p=$ $0.036)$, and CAT $-2.9 \pm 6.1(p=0.14)$ were observed in the $32 \mathrm{~W}$ group compared to baseline. The $29 \mathrm{~W}$ group had changes in $\mathrm{FEV}_{1}$ of $57 \pm 82 \mathrm{~mL}(p=0.0272), \mathrm{FVC} 238$ $\pm 316 \mathrm{~mL}(p=0.0188)$, SGRQ-C $-1.9 \pm 12.5(p=0.6166)$, and CAT $0.3 \pm 7.8(p=0.8898)$ compared to their baseline. The difference between groups did not reach statistical significance (Table 3, Fig. 3).

An exploratory post hoc bivariate analysis was performed on 1-year $\mathrm{FEV}_{1}$ or SGRQ-C outcomes and is listed in online supplemental Table S5.

\section{Open-Label Confirmation Study}

All patients in the open-label study received TLD with $32 \mathrm{~W}$. Patients in this study had similar baseline characteristics and procedural details (Table 1) to those in the randomized dosing phase group, with the exception of more frequent "incomplete" circumferential TLD treatment of the right lung ( $45 \%$ with $<4$ activations in the right lung) in the open-label study. This was due to the 
Table 3. Changes at 1-year from baseline washout off bronchodilators

\begin{tabular}{|c|c|c|c|c|}
\hline & \multicolumn{3}{|c|}{ Dosing group } & \multirow{2}{*}{$\begin{array}{l}\text { Confirmation group } \\
32 \mathrm{~W} \\
(n=16)\end{array}$} \\
\hline & $\begin{array}{l}32 \mathrm{~W} \\
(n=15)\end{array}$ & $\begin{array}{l}29 \mathrm{~W} \\
(n=15)\end{array}$ & $\begin{array}{l}p \text { value } \\
(32 \text { vs. } 29 \mathrm{~W})\end{array}$ & \\
\hline $\mathrm{FEV}_{1}, \mathrm{~mL}$ & $94 \pm 228$ & $57 \pm 82$ & 0.6050 & $34 \pm 174$ \\
\hline FVC, mL & $212 \pm 497$ & $238 \pm 316$ & 0.8761 & $208 \pm 528$ \\
\hline TLC, L & $0.04 \pm 0.21$ & $0.01 \pm 0.30$ & 0.8173 & $0.19 \pm 0.7$ \\
\hline $\mathrm{RV}, \mathrm{L}$ & $-0.12 \pm 0.52$ & $-0.23 \pm 0.55$ & 0.6311 & $-0.01 \pm 1.0$ \\
\hline IC, L & $-0.04 \pm 0.28$ & $-0.07 \pm 0.44$ & 0.8374 & $0.06 \pm 0.3$ \\
\hline SGRQ-C & $-7.5 \pm 10$ & $-1.9 \pm 12$ & 0.2534 & $-6.1 \pm 21$ \\
\hline CAT & $-2.9 \pm 6.1$ & $0.3 \pm 7.8$ & 0.2800 & $-6.2 \pm 9.6$ \\
\hline EQ-5D & $0.1 \pm 0.2$ & $0.0 \pm 0.2$ & 0.6930 & $0.1 \pm 0.2$ \\
\hline EQ-5D VAS & $9.1 \pm 21$ & $3.2 \pm 14$ & 0.4229 & $0 \pm 22$ \\
\hline mMRC & $0.1 \pm 0.9$ & $0.0 \pm 0.7$ & 0.7900 & $-0.2 \pm 0.7$ \\
\hline TDI & $0.5 \pm 2.7$ & $-0.7 \pm 4.3$ & 0.4516 & $1.3 \pm 3.8$ \\
\hline Exercise endurance*, min & $-2.7 \pm 8$ & $-0.3 \pm 4.7$ & 0.7969 & $-2.1 \pm 9.3$ \\
\hline
\end{tabular}

* Performed at $75 \%$ of Wmax.

$\mathrm{FEV}_{1}$, forced expiratory volume in 1-s; FVC, forced vital capacity; TLC, total lung capacity; RV, residual volume; IC, inspiratory capacity; SGRQ-C, COPD specific St. Georges Respiratory questionnaire; CAT, COPD Assessment Test; EQ-5D, EuroQol Health Assessment - 5 dimensions; mMRC, Modified Medical Research Council dyspnea scale; TDI, Transitional dyspnea index.

Fig. 3. Changes in secondary efficacy outcomes from baseline in the randomized dose evaluation study. The change in (a) $\mathrm{FEV}_{1}$ response and (b) SGRQ-C from washout baseline at 1 year in the 29 and 32 $\mathrm{W}$ dosing groups. $\mathrm{FEV}_{1}$, forced expiratory volume in $1 \mathrm{~s}$; TLD, targeted lung denervation; SGRQ-C, St. George's Respiratory Questionnaire.

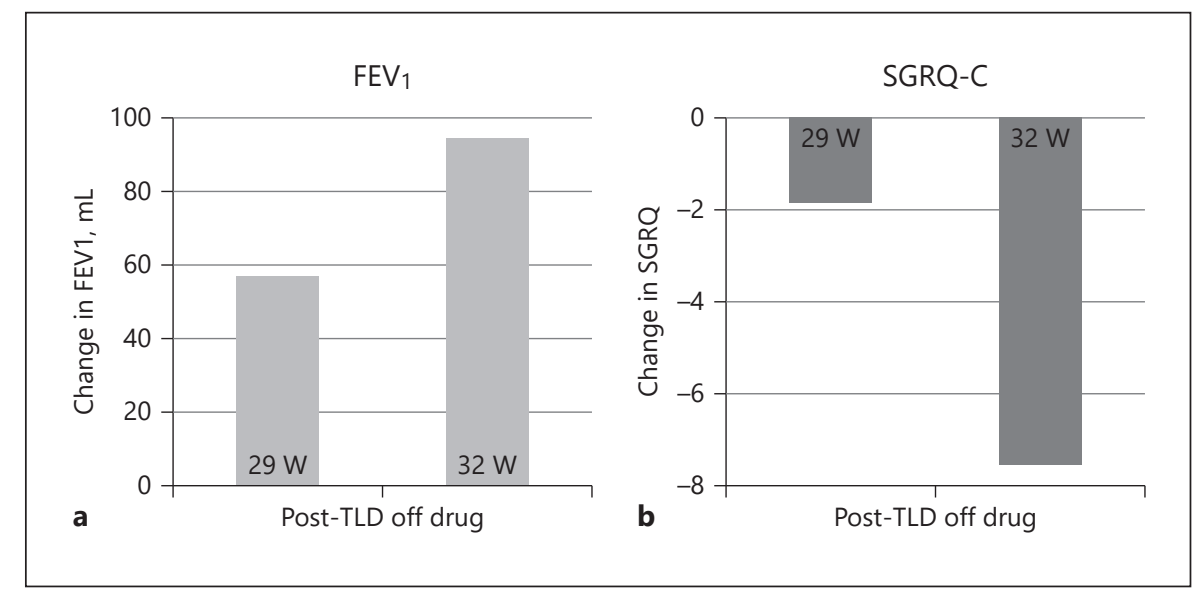

proximity of the RF electrode to the esophageal balloon, compared with the randomized dosing study (16\% with $<4$ activations in the right lung; Table 1 ). Acute procedure success was $94 \%$ (15/16) with the RF catheter being unable to be re-inserted after removal for cleaning in 1 patient. One-year follow-up data were available for $88 \%$ $(14 / 16)$ of patients (Fig. 1). When considering SAEs adjudicated as related to TLD, only 1 out of 16 patients (6\%) had an SAE in the 1-month posttreatment period of the confirmation study (Fig. 4). Overall SAE rates during the course of the study are listed in Table 2. Secondary end- points are shown in Table 3. Clinically meaningful improvements were observed for the SGRQ-C (57\% of patients with $\geq 4$ point drop) and CAT (79\% of patients with $\geq 2$ point drop) score at 1 year.

\section{Discussion}

The present study demonstrated overall safety and feasibility of TLD in patients with moderate to severe COPD. Reports of gastric adverse events during the randomized 
Fig. 4. SAE adjudicated as directly related to TLD. The figure depicts the SAEs that were adjudicated as directly related to the TLD procedure broken out by power, study group, and time period post procedure. The patients treated at $29 \mathrm{~W}$ during the randomized dosing phase of the study experienced the highest rate of TLD-related SAEs in the 40 days following the procedure. The procedural, protocol, and training changes evaluated in the confirmation phase resulted in the lower post procedure TLD-related SAEs. SAE, serious adverse event.

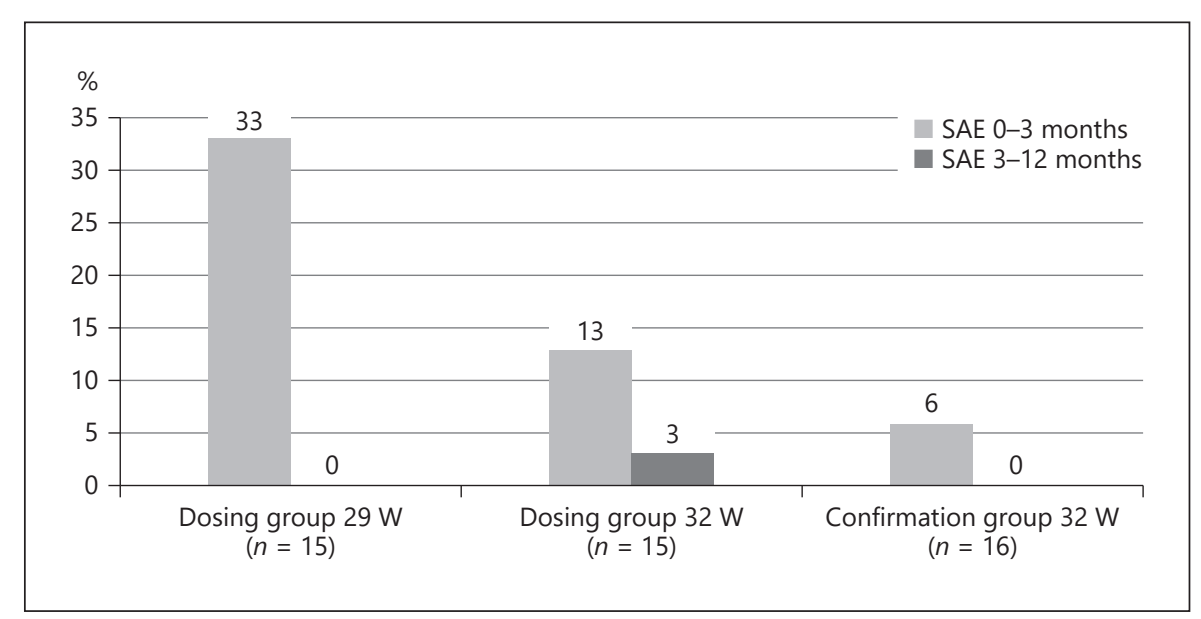

dosing study prompted procedural enhancements, with a subsequent reduction in treatment-related gastric side effects confirmed in an open-label phase.

TLD is a novel bronchoscopic approach that disrupts the parasympathetic innervation of the lungs, while minimizing damage to tissues of the main bronchi through the use of a dual cooling method $[11,13]$. Post procedure, the distal segments of the targeted nerve fibers are disconnected from their proximal segments due to thermal injury [22-26]. They undergo the process of Wallerian degeneration that degrades these distal fibers all the way out to their peripheral endings, with persistent cessation of acetylcholine release $[27,28]$.

Early in the randomized dosing phase of the study, gastrointestinal SAEs were observed. The symptoms were similar to side effects reported in patients who undergo catheter ablation of atrial fibrillation. Ablation in the atrium is in close proximity to the esophagus, on the outside of which runs the esophageal-vagal plexus that goes on to innervate the stomach [29-31]. In fact, gastrointestinal complications such as gastroparesis, esophageal thermal lesions, esophageal ulcers, and other signs of symptomatic periesophageal vagal plexus injury were reported in as high as $40 \%$ of patients treated for atrial fibrillation [32]. In response to reports from patients with impaired gastric motility in the current study, the study was halted and procedural modifications were implemented to address these events. The procedural change utilized an esophageal balloon to allow the physician to visualize the esophagus and make a fluoroscopic assessment of the distance between the RF electrode and the esophagus. A treatment plan was developed based on extensive preclinical testing that allowed for a reduction in energy levels for activations at sites close to the esophagus. The proto- col, procedural, and training modifications reduced the incidence of SAEs that could be directly attributed to the procedure. The rate of SAEs dropped by more than half in the remaining patients treated in the randomized dosing phase, and gastrointestinal SAEs were eliminated in the confirmation phase.

The higher energy dose was selected for the open-label study due to a trend toward more favorable clinical outcomes, that is, improvements in lung function and quality of life data, in the absence of differences in the adverse events profile between the 2 energy groups in the blinded randomized phase of the study. Noteworthy, there were no changes in medication during follow-up.

In contrast to the first-generation device of TLD [11, 13], which required rigid bronchoscopy, the technology used in the current study allowed placement of the RF catheter through the working channel of a flexible bronchoscope. This second-generation device incorporated a longer electrode, which reduced the number of required RF activations by $50 \%$ and shortened the procedure time. Compared to the first-in man reports of TLD $[11,13]$, the current study evaluated 2 slightly higher dose power levels that were based on extensive preclinical work [22-26] and were intended to maximize efficacy while maintaining safety.

Consequently, the primary outcome in the current safety study was the rate of acute airway wall effects. These effects were observed in $15 \%$ of treated patients, with full resolution of all events at follow-up visits. In comparison to other bronchoscopic treatments for COPD, TLD appears to have a low rate of respiratory-related adverse events in the perioperative period. In contrast, patients treated with endobronchial coils experience rates of pneumonia causing hospitalization as high as $25 \%$ [33] and pneumothorax 
rates reported as high as 30\% [34,35] for valve treatment in patients with emphysematous phenotype of COPD [36]. TLD appears to provide a favorable clinical benefit with consistent respiratory safety, according to the current report and the previous first-in human studies.

Following TLD in the dosing phase, 1 patient exhibited a deep ulceration at the medial side of the right main stem bronchus with a mucosal fistula through the thin tissue of the carina and a partial occlusion of the right upper lobe bronchus. Analysis of videos from clinical procedures and bench top studies of ablations with the device (unpublished data) indicate that the observed ulceration and fistula were likely caused by poor balloon contact and treatment along the medial wall of the right main stem. The cooling fluid circulated underneath the electrode and through the balloon during energy delivery cools the surface of the airway wall. When the balloon fails to make appropriate contact with the airway wall, heat from the energy delivery builds up at the surface of the airway which can cause ulceration. Additionally, the medial wall of the right main bronchi has been found to be susceptible to overheating due to airway anatomy. The right medial treatment location is near the main carina, which is a thinner tissue layer than that of other treatment locations. Heat likely accumulates in thinner tissue due to a decrease in heat loss from tissue perfusion. The results of both of these observations were changes to the implementation of the procedure that ensure the contact of the balloon to the airway wall and lowering power in medial location of the right main stem bronchi regardless of distance from the esophagus. The absence of significant ulcerations or fistula in the conformation portion of the study is indicative of the impact of the procedural changes.

Improvements observed in quality of life and COPD symptom scores appear to indicate a dose-response relationship of TLD, with patients treated at higher energy levels ( $32 \mathrm{~W}$ ) experiencing clinically meaningful benefits using common threshold for the SGRQ-C ( -4 points) [ 16 , 37]. However, we have to acknowledge that the sample size of the current study was powered to formally assess neither noninferiority of safety outcomes nor superiority of efficacy outcomes between the individual dosing groups. This may also potentially explain the absence of symptomatic improvements using other patient-reported tests, such as the mMRC. In this context, it needs to be acknowledged that different symptom scores may present different aspects of the disease, with the mMRC not equally representing the full spectrum of symptomatic burden compared with other self-reported questionnaires [38].

TLD Dosing Study
Another potential shortcoming of our study is the absence of a control group. Nevertheless, the blinded dose response observed in the current study suggests an intervention effect. A randomized, sham-controlled study (AIRFLOW-2 NCT02058459) is currently under way to understand the impact of this potential limitation.

In summary, the current study evaluated a novel second-generation TLD device. During the early phase of this study, procedural changes were implemented that markedly improved the safety profile of the procedure. Ultimately, the study demonstrated safety and feasibility of TLD using a novel device design in patients with moderate-to-severe COPD.

\section{Acknowledgments}

We would like to thank the dedicated team of investigators, coordinators, and safety team members who conducted this study. We give thanks to the willing patients who participated in this study and the families that helped support them. Special thank you to Martin Mayse, MD, who conceived of TLD to treat obstructive lung diseases.

\section{Statement of Ethics}

Subjects who participated in the AIRFLOW 1 clinical trial have given their informed consent to participate in this trial. The study protocol was approved by each research institutions committee on human research.

\section{Disclosure Statement}

All clinical trial expenses were reimbursed by the study sponsor (Nuvaira, Inc.). A.V. and D.-J.S. are the co-principle investigators for this study. All other authors declare that they have no conflicts of interest to disclose.

\section{Funding Sources}

The AIRFLOW 1 clinical trial was funded by Nuvaira Inc., Minneapolis, MN, USA.

\section{Author Contributions}

A.V. and D.-J.S. assisted in protocol development with the study sponsor and were involved in data analysis. All other authors participated in patient recruitment and interpretation of the data and assisted in the development of the final manuscript. The corresponding author had full access to all data in the study and had final responsibility for the decision to submit for publication. 


\section{Members of the AIRFLOW-1 Study Group Were as Follows}

Data and Safety Monitoring Board: A. Chen (chair), J. Gorden, Z. Issa, G. McDonald, C. Pulling. Clinical Events Committee: R. Aalbers, D. Ferrera, L. Leh. Otto-Wagner-Spital, Vienna, Austria: Dr. Arschang Valipour, Dr. Christine Abele, Dr. Irene Firlinger, Kiran Kothakuzhakal, Marina Duller, CHU Saint-Pierre, Brussels, Belgium: Prof. Vincent Ninane, Dr. Inge Muylle, Dr. Peter Rummens, Frederique De Cock, AZ Leuven - Campus Gasthuisberg, Leuven, Belgium: Prof. Wim Janssens, Prof. Christophe Dooms, Kristien DeBent, CHU de Grenoble - Hopital Michallon Grenoble, France: Prof. Christophe Pison, Dr. Amandine Briault, Dr. Francois Arbib, Marie Jondot, Prof. Gilbert Ferretti, CHU de Lille - Hopital Calmette Lille, France: Dr. Thierry Perez, Dr. Clem- ent Fournier, Prof. Regis Matran, Dr. Michele Catto, Dr. Nathalie Bautin, Dr. Virginie De Broucker, Dr. Marie Willemin, Dr. Anne Prevotat, Dr. Ludivine Wemeau, Dr Alice Gicquello, Morgane Foulon, Hasna Camara, CHU de Reims - Hopital Maison Blanche Reims, France : Prof. Gaetan Deslee, Dr. Herve Vallerand, Dr. Sandra Dury, Delphine Gras, Margaux Bonnaire-Verdier, CHRU de Strasbourg - Nouvel Hopital Civil Strasbourg, France: Prof. Romain Kessler, Dr. Sandrine Hirschi, Dr. Michele Porzio, Dr. Tristan Degot, Dr. Mathieu Canuet, Dr. Armelle Schuller, Julien Stauder, Sahra Ali Azouaou, Royal Brompton and Harefield NHS Trust, Chelsea and Westminster Hospitals, London, UK: Prof. Pallav L. Shah, Dr. Justin Garner, Dr. Karthi Srikanthan, Ms. Cielito Caneja, Dr. John Thornton, University Medical Centre Groningen, Groningen, The Netherlands: Dr. Dirk-Jan Slebos, Dr. Nick Ten Hacken, Dr. Jorine Hartman, Sonja Augustijn, Dr. Karin Klooster

\section{References}

1 Belmonte KE. Cholinergic pathways in the lungs and anticholinergic therapy for chronic obstructive pulmonary disease. Proc Am Thorac Soc. 2005;2(4):297-304; discussion 311-2.

2 Gosens R, Zaagsma J, Meurs H, Halayko AJ. Muscarinic receptor signaling in the pathophysiology of asthma and COPD. Respir Res. 2006 May;7(1):73.

3 Kolahian S, Gosens R. Cholinergic regulation of airway inflammation and remodelling. J Allergy (Cairo). 2012;2012:681258.

4 Oenema TA, Kolahian S, Nanninga JE, Rieks D, Hiemstra PS, Zuyderduyn S, et al. Pro-inflammatory mechanisms of muscarinic receptor stimulation in airway smooth muscle. Respir Res. 2010 Sep;11(1):130.

5 Canning BJ, Mori N, Mazzone SB. Vagal afferent nerves regulating the cough reflex. Respir Physiol Neurobiol. 2006 Jul;152(3): 223-42.

6 Gross NJ, Skorodin MS. Role of the parasympathetic system in airway obstruction due to emphysema. N Engl J Med. 1984 Aug;311(7): 421-5.

7 Mazzone SB, Canning BJ. Synergistic interactions between airway afferent nerve subtypes mediating reflex bronchospasm in guinea pigs. Am J Physiol Regul Integr Comp Physiol. 2002 Jul;283(1):R86-98.

8 Bleecker ER. Cholinergic and neurogenic mechanisms in obstructive airways disease. Am J Med. 1986 Nov;81(5 5A):93-102.

9 Zaccone EJ, Undem BJ. Airway Vagal Neuroplasticity Associated with Respiratory Viral Infections. Lung. 2016 Feb;194(1):25-9.

10 Tryfon S, Kontakiotis T, Mavrofridis E, Patakas D. Hering-Breuer reflex in normal adults and in patients with chronic obstructive pulmonary disease and interstitial fibrosis. Respiration. $2001 ; 68: 140-4$.
11 Slebos DJ, Klooster K, Koegelenberg CF, Theron J, Styen D, Valipour A, et al. Targeted lung denervation for moderate to severe COPD: a pilot study. Thorax. 2015 May;70(5): 411-9.

12 Koegelenberg CF, Theron J, Slebos DJ, Klooster K, Mayse M, Gosens R. Antimuscarinic Bronchodilator Response Retained after Bronchoscopic Vagal Denervation in Chronic Obstructive Pulmonary Disease Patients. Respiration. 2016;92(1):58-60.

13 Valipour A, Asadi S, Pison C, Jondot M, Kessler $\mathrm{R}$, Benneddif $\mathrm{K}$, et al. Long-term safety of bilateral targeted lung denervation in patients with COPD. Int J Chron Obstruct Pulmon Dis. 2018 Jul;13:2163-72.

14 Miller MR, Crapo R, Hankinson J, Brusasco V, Burgos F, Casaburi R, et al.; ATS/ERS Task Force. General considerations for lung function testing. Eur Respir J. 2005 Jul;26(1):15361.

15 Meguro M, Barley EA, Spencer S, Jones PW. Development and Validation of an Improved, COPD-Specific Version of the St. George Respiratory Questionnaire. Chest. 2007 Aug; 132(2):456-63.

16 Kon SS, Canavan JL, Jones SE, Nolan CM, Clark AL, Dickson MJ, et al. Minimum clinically important difference for the COPD Assessment Test: a prospective analysis. Lancet Respir Med. 2014 Mar;2(3):195-203.

17 Nolan CM, Longworth L, Lord J, Canavan JL, Jones SE, Kon SS, et al. The EQ-5D-5L health status questionnaire in COPD: validity, responsiveness and minimum important difference. Thorax. 2016 Jun;71(6):493-500.

18 Bestall JC, Paul EA, Garrod R, Garnham R, Jones PW, Wedzicha JA. Usefulness of the Medical Research Council (MRC) dyspnoea scale as a measure of disability in patients with chronic obstructive pulmonary disease. Thorax. 1999 Jul;54(7):581-6.
19 American Thoracic Society; American College of Chest Physicians. ATS/ACCP Statement on cardiopulmonary exercise testing. Am J Respir Crit Care Med. 2003;167(2):211-77.

20 Maltais F, Hamilton A, Marciniuk D, Hernandez P, Sciurba FC, Richter K, et al. Improvements in symptom-limited exercise performance over $8 \mathrm{~h}$ with once-daily tiotropium in patients with COPD. Chest. 2005 Sep; 128(3):1168-78.

21 Rentz AM, Kahrilas P, Stanghellini V, Tack J, Talley NJ, de la Loge C, et al. Development and psychometric evaluation of the patient assessment of upper gastrointestinal symptom severity index (PAGI-SYM) in patients with upper gastrointestinal disorders. Qual Life Res. 2004 Dec;13(10):1737-49.

22 Johnson PJ, Mayse M, Rouw K. Targeted lung denervation; an evaluation of power dose effect. Eur Respir J. 2017;50:PA821.

23 Mayse M, Hummel JP, Johnson PJ, Rouw K. Improved pulmonary resistance in healthy sheep following Targeted lung denervation (TLD). Eur Respir J. 2017;50:PA819.

24 Mayse M, Johnson P, Hummel J. Importance of surface cooling during targeted lung denervation for COPD. Eur Respir J. 2014;44:1793.

25 Mayse M, Johnson P, Rouw K. Demonstration of pulmonary denervation using the Hering-Breuer reflex following Targeted lung denervation (TLD). Eur Respir J. 2017; 50:PA820.

26 Mayse M, Johnson P, Streeter J, Deem M, Hummel J. Targeted lung denervation in the healthy sheep model - A potential treatment for COPD. Eur Respir J. 2014;44:943.

27 Waller A. Experiments on the section of the glossopharyngeal and hypoglossal nerves of the frog, and observations of the alterations produced thereby in the structure of their primitive fibres. Philos Trans R Soc Lond. 1850;140:423-9. 
28 Wood MD, Johnson PJ, Myckatyn TM. Nerve Surgery. Stuttgart, New York: Georg Thieme Verlag; 2015. pp. 1-40.

29 Banki F, Mason RJ, DeMeester SR, Hagen JA, Balaji NS, Crookes PF, et al. Vagal-sparing esophagectomy: a more physiologic alternative. Ann Surg. 2002 Sep;236(3):324-35; discussion 335-6.

30 Doubilet H, Shafiroff BG, Mulholland JH. The Anatomy of the Peri-Esophageal Vagi. Ann Surg. 1948 Jan;127(1):128-35.

31 Herbella FA, Regatieri CV, Moreno DG, Matone J, Del Grande JC. Vagal integrity in vagal-sparing esophagectomy: a cadaveric study. Dis Esophagus. 2006;19(5):406-9.

32 Lakkireddy D, Reddy YM, Atkins D, Rajasingh J, Kanmanthareddy A, Olyaee $\mathrm{M}$, et al. Effect of atrial fibrillation ablation on gastric motility: the atrial fibrillation gut study. Circ Arrhythm Electrophysiol. 2015 Jun;8(3):531-
33 Kontogianni K, Gerovasili V, Gompelmann D, Schuhmann M, Hoffmann H, Heussel CP, et al. Coil therapy for patients with severe emphysema and bilateral incomplete fissures effectiveness and complications after 1-year follow-up: a single-center experience. Int Chron Obstruct Pulmon Dis. 2017 Jan;12: 383-94.

34 Valipour A, Slebos DJ, Herth F, Darwiche K, Wagner M, Ficker JH, et al.; IMPACT Study Team. Endobronchial Valve Therapy in Patients with Homogeneous Emphysema. Results from the IMPACT Study. Am J Respir Crit Care Med. 2016 Nov;194(9):1073-82.

35 Valipour A, Slebos DJ, de Oliveira HG, Eberhardt R, Freitag L, Criner GJ, et al. Expert statement: pneumothorax associated with endoscopic valve therapy for emphysema-potential mechanisms, treatment algorithm, and case examples. Respiration. 2014;87(6):51321.
36 Slebos DJ, Shah PL, Herth FJ, Valipour A. Endobronchial Valves for Endoscopic Lung Volume Reduction: Best Practice Recommendations from Expert Panel on Endoscopic Lung Volume Reduction. Respiration. 2017;93(2): $138-50$

37 Jones PW, Beeh KM, Chapman KR, Decramer M, Mahler DA, Wedzicha JA. Minimal clinically important differences in pharmacological trials. Am J Respir Crit Care Med. 2014 Feb;189(3):250-5.

38 Miravitlles M, Koblizek V, Esquinas C, Milenkovic B, Barczyk A, Tkacova R, et al. Determinants of CAT (COPD Assessment Test) scores in a population of patients with COPD in central and Eastern Europe: the POPE study. Respir Med. 2019 Apr;150:141-8. 